\title{
Effects of isotretinoin on body mass index, serum adiponectin, leptin, and ghrelin levels in acne vulgaris patients
}

\author{
Bengu Cevirgen Cemil' ${ }^{1}$, Havva Hilal Ayvaz ${ }^{1}$, Gulfer Ozturk², Can Ergin ${ }^{1}$, Havva Kaya Akıs ${ }^{1}$, Muzeyyen Gonul', \\ Ercan Arzuhal ${ }^{2}$
}

${ }^{1}$ Department of Dermatology, Ministry of Health Diskapi Yildirim Beyazit Education and Research Hospital, Ankara, Turkey ${ }^{2}$ Department of Biochemistry, Ministry of Health Diskapi Yildirim Beyazit Education and Research Hospital, Ankara, Turkey

Adv Dermatol Allergol 2016; XXXIII (4): 294-299

DOI: $10.5114 /$ pdia.2016.56928

\begin{abstract}
Introduction: Isotretinoin has been successfully used for the treatment of acne vulgaris.

Aim: To investigate the effects of isotretinoin on body mass index (BMI), to determine whether isotretinoin causes any changes in serum adiponectin, leptin, and ghrelin levels in acne vulgaris patients, and to correlate variables. Material and methods: Thirty-two patients were included in this study. Oral isotretinoin was begun at a dose of $0.5-0.6 \mathrm{mg} / \mathrm{kg}$ and raised to $0.6-0.75 \mathrm{mg} / \mathrm{kg}$. Pretreatment and posttreatment third-month BMI and adiponectin, leptin, and ghrelin serum levels were measured.

Results: The pre- and posttreatment BMI values were not significantly different. In addition, serum adiponectin and leptin levels were significantly increased following isotretinoin therapy while serum ghrelin levels were not different. Conclusions: Isotretinoin may exert its anti-inflammatory activity by increasing leptin and adiponectin levels.
\end{abstract}

Key words: acne vulgaris, adipocytokines, body mass index, ghrelin, isotretinoin.

\section{Introduction}

Acne is a chronic inflammatory disorder of the pilosebaceous units in the skin. Although it commonly affects the majority of the adolescent population [1], it is also prevalent in adults [2]. The pathogenesis of acne is multifactorial and includes hormonal, inflammatory, and immunologic mechanisms [3, 4]. There are four processes that play a pivotal role in the formation of acne lesions as follows: inflammatory mediators released into the skin, alteration of the keratinization process leading to comedones, increased and altered sebum production under androgen control (or increased androgen receptor sensitivity), and follicular colonization by Propionibacterium acnes. The sequence of and the interactions between these events remain unclear [5]. Harrison et al. reported that the pathways of differentiation in sebaceous glands and adipocytes may be similar; therefore, further understanding of sebaceous gland differentiation and lipogenesis as well as potential therapies for sebaceous gland disorders may be gleaned from what is known about adipocyte differentiation [6]. The expression of galectin-12, resistin, sterol response element binding protein-1, and stearoyl-CoA desaturase (SCD), all of which are involved in adipocyte differentiation, has also been reported in sebaceous glands. The fact that these adipogenic factors have also been detected in human sebaceous glands suggests that they may play a similar role in sebocyte differentiation as in adipocyte differentiation [6]. Because adipokines affect sebocytes, adipokines may also play a role in the pathogenesis of acne vulgaris.

Isotretinoin (13-cis retinoic acid) is widely used to treat severe cystic or recalcitrant acne. Isotretinoin is the most potent pharmacological inhibitor of sebum secretion; it causes a reduction in the size of sebaceous glands, it causes sebocytes to appear undifferentiated, and it leads to a decrease in lipid accumulation. However, the exact mechanisms behind the effects of isotretinoin are not yet known [7].

Address for correspondence: Bengu Cevirgen Cemil MD, Department of Dermatology, Ministry of Health Diskapi Yildirim Beyazit Education and Research Hospital, Ankara, Turkey, phone: +90 312 5962083, mobile: +90 533 6296195, fax: +90 31247295 34, e-mail: dbcemil@yahoo.com Received: 3.08.2015, accepted: 31.08.2015. 
Adipose tissue is a major site for storage of vitamin A derivates (collectively named retinoids); therefore, it plays an active role in their homeostasis and metabolism [8]. Moreover, adipose tissue is a known target organ for retinoic acid as retinoid and retinoid $X$ receptors are expressed in adipose tissue [9]. In addition, white adipose tissue acts as an endocrine organ and produces a variety of hormones (adipocytokines), including leptin, adiponectin, tumor necrosis factor $\alpha$ (TNF- $\alpha$ ) and angiotensin II (Ang II), all of which influence lipid metabolism, systemic insulin sensitivity and inflammation [10]. In vitro and in vivo studies have shown that retinoids affect adipocytederived leptin levels, and that this effect is primary (i.e. not a consequence of the reduction in adipose tissue mass) [8].

To our knowledge, few studies have focused on changes in body mass index (BMI) in humans treated with isotretinoin [11-15], and only one reported associations between adipocytokines and isotretinoin treatment [13]. In addition, investigation of correlations between global acne grading system (GAGS) and adipocytokines, and pre-post treatment levels of adipocytokines has not been evaluated previously. Therefore, this study aimed to determine the effects of isotretinoin therapy on BMI, leptin, adiponectin, and ghrelin levels in patients with acne vulgaris.

\section{Aim}

The aim of this study was to investigate the effects of isotretinoin on $\mathrm{BMI}$, to determine whether isotretinoin causes any changes in serum adiponectin, leptin, and ghrelin levels in acne vulgaris patients, and to correlate variables.

\section{Material and methods}

This study consisted of patients who were admitted to the dermatology outpatient clinic between December 2013 and May 2014. A total of 32 patients (out of 48) suffering from acne vulgaris met the inclusion criteria in this study (12/20 females/males; mean age: $18.9 \pm 2.57$ years). Sixteen patients were excluded from the study because they did not complete a minimum treatment period of three months or because they did not undergo the required tests needed to monitor their treatment. The study group was selected from a group of male and non-pregnant female patients who did not want to become pregnant and who had moderate to severe nodulocystic acne. The GAGS was used to evaluate acne severity. Briefly, each of six locations (forehead, right cheek, left cheek, nose, chin, chest and upper back) was given a score between 0 and 4 and was assigned a factor on the basis of size. A score of 19-30 indicates moderate acne while a score of 31-38 indicates severe acne [16]. Patients were excluded from the study if they met any of the following criteria: previously diagnosed diabetes mellitus, hyperthyroidism, pituitary disease, hypogonadism, polycystic ovary syndrome, chronic liver disease, chronic renal disease, and other inflammatory or infectious disease, or a recent history of psychiatric, mood or depressive disorders. The protocol for this study was approved by the Diskapi Yildirim Beyazit Educational and Research Hospital ethics committee, and informed consent was obtained from all of the patients or their parents.

At recruitment and after 3 months of isotretinoin treatment, the weight and height of all subjects were recorded, and the BMI was calculated (weight (kg) divided by height ( $\mathrm{m}$ ) squared). Isotretinoin therapy was initiated at a dose of $0.5-0.6 \mathrm{mg} / \mathrm{kg} /$ day body weight, and after 1 month, the dose was adjusted to $0.6-0.75 \mathrm{mg} / \mathrm{kg} /$ day as a maintenance dosage. Biochemical parameters (total cholesterol, triglycerides, high-density lipoprotein cholesterol (HDL-C), low-density lipoprotein cholesterol (LDL-C), leptin, adiponectin, and ghrelin) were screened immediately prior to initiation (pretreatment) and after 3 months of isotretinoin treatment (posttreatment). Blood samples were obtained after $12 \mathrm{~h}$ of fasting. Blood samples were centrifuged at $2500 \times \mathrm{g}$ for $15 \mathrm{~min}$ at $4^{\circ} \mathrm{C}$ within $30 \mathrm{~min}$ of collection, and serum samples were stored at $-70^{\circ} \mathrm{C}$ until further analysis. Measurements of total cholesterol (reference range: 0-200 mg/dl), HDL-C (reference range: 40-60 mg/dl), LDL cholesterol (reference range: 0-100 mg/ dl) and triglycerides (reference range: 0-250 mg/dl) were performed using a Siemens Advia 2400 with commercially available kits (Siemens Healthcare Diagnostics Inc., Tarrytown, USA). Measurements of ghrelin (Phoenix Pharmaceuticals, California, USA), leptin (DRG Diagnostic International, Inc., USA) and adiponectin (eBioscience Inc. USA) were performed using an EPOCH system (BioTek Instruments, Inc, USA) with commercially available enzyme-linked immunosorbent assay (ELISA) kits. Ghrelin and leptin levels were expressed as nanograms/milliliter $(\mathrm{ng} / \mathrm{ml})$ and adiponectin levels were expressed as micrograms/liter $(\mu \mathrm{g} / \mathrm{l})$. All of the samples were evaluated for the above biochemical parameters at the same time.

\section{Statistical analysis}

SPSS (Statistical Package for the Social Sciences version 16.0) software was used to analyze the data. Descriptive statistics for variables were expressed as means \pm standard deviations. The Wilcoxon signed rank test was used to compare pretreatment and posttreatment data. To compare male and female patients' data, MannWhitney $U$ test was used. Pearson correlation was used to analyze the correlation between the variables. Values of $p<0.05$ were considered statistically significant for all analyses.

\section{Results}

Thirty two patients (62.5\% - males and $37.5 \%$ - females) were included in this study, and their mean age was $18.0 \pm 2.57$ years (range: $16-25$ years). The main clini- 
Table 1. Main clinical characteristics

\begin{tabular}{lc}
\hline Parameter & Result \\
\hline Age, mean \pm SD [years] & $18.9 \pm 2.57$ \\
\hline Gender (male/female) & $20 / 12$ \\
\hline BMI, mean \pm SD $\left[\mathrm{kg} / \mathrm{m}^{2}\right]$ & $21.86 \pm 3.56$ \\
\hline Acne duration, mean \pm SD [years] & $4.03 \pm 2.36$ \\
\hline Positive family history (\%) & 84.4 \\
\hline Acne severity score (\%): & 71.9 \\
\hline Moderate (19-30) & 28.1 \\
\hline Severe (31-38)
\end{tabular}

cal characteristics of the patients are presented in Table 1. Following isotretinoin treatment, BMI was increased in 15 patients, decreased in 14 patients, and unchanged in 2 patients $(p>0.05)$. Blood lipid and hormonal parameters before and after isotretinoin treatment are summarized in Table 2. Serum levels of total cholesterol, LDL-C, and triglycerides $(p<0.05)$ were significantly increased following isotretinoin treatment, while HDL-C levels did not differ $(p>0.05)$. Adiponectin and leptin levels were significantly increased following isotretinoin treatment $(p<0.05)$. There were no significant changes in the levels of ghrelin after isotretinoin treatment. When adiponectin, leptin, and ghrelin levels are evaluated separately in men and women before and after isotretinoin treatment, a significant difference was shown for leptin values between male and female patients $(p<0.05)$. Higher leptin levels were found in women patients than male patients. Both adiponectin and ghrelin values did not reveal any significant difference between male and female patients $(p>0.05)$. In addition, we found that leptin and adiponectin levels increased significantly in patients who had significantly increased BMI after isotretinoin treatment; however, these patients did not have any significant changes in ghrelin levels. Patients who had a decrease in $\mathrm{BMI}$ after isotretinoin treatment showed a significant increment in adiponectin levels $(p<0.05)$; but there were no changes in leptin and ghrelin levels $(p>0.05)$. The insufficient number of samples for both groups may be the reason of non-significant difference. We did not observe any correlation between GAGS and variables studied.

\section{Discussion}

Sebaceous glands are present all over the human body, except on the palms of the hands and soles of the feet. They are usually found in association with hair follicles [17]. The sebaceous gland is a holocrine gland, meaning that the glandular secretion consists of cells from the gland itself. The sebaceous gland contains two kinds of sebocytes: peripheral cells and central cells. The peripheral cells are immature cells that are cuboidal or flattened and do not contain lipids [18]. The central cells are larger than the peripheral cells, and the majority of this size increase is due to the elevated amount of cytoplasmic lipids. Adipocytes are most like sebocytes. Both cell types have a similar physiology, which is the accumulation of lipids. Sebocytes release lipids that eventually make their way to the skin surface, while adipocyte lipids have energy-storing functions. Both adipocytes and sebocytes have similar receptors and express enzymes important for lipid production (e.g., LDL, liver X receptor (LXR), diacylglycerol acyltransferase, and SCD1). Treatment of adipocytes and sebocytes with LXR agonists causes a decrease in lipogenesis [18].

Oral isotretinoin is generally reserved for severe, recalcitrant, nodular acne that is unresponsive to topical therapy. Its mechanism of action and side effect profile is not yet completely understood [19]. Isotretinoin significantly decreases sebum production [20] and growth of $P$. acnes [21]; in addition, it reverses hyperkeratinization and reduces inflammation. Although it is an effective therapy for acne, isotretinoin is associated with significant adverse effects, including cheilitis, dry skin and mucous membranes [22], epistaxis, increased risk of cu-

Table 2. Comparisons of blood lipid and hormonal parameters before and after isotretinoin treatment

\begin{tabular}{|c|c|c|c|}
\hline Parameter & $\begin{array}{l}\text { Pretreatment } \\
\text { Mean } \pm \text { SD }\end{array}$ & $\begin{array}{l}\text { Posttreatment } \\
\text { Mean } \pm \text { SD }\end{array}$ & $P$-value \\
\hline Total cholesterol [mg/dl] & $143.31 \pm 23.49$ & $165.91 \pm 29.46$ & $<0.05$ \\
\hline Triglycerides [mg/dl] & $74.66 \pm 27.70$ & $91.03 \pm 42.04$ & $<0.05$ \\
\hline LDL cholesterol [mg/dl] & $79.38 \pm 24.09$ & $93.38 \pm 23.97$ & $<0.05$ \\
\hline HDL cholesterol [mg/dl] & $44.94 \pm 9.25$ & $42.63 \pm 6.98$ & $>0.05$ \\
\hline $\mathrm{BMI}\left[\mathrm{kg} / \mathrm{m}^{2}\right]$ & $21.86 \pm 3.56$ & $21.85 \pm 3.59$ & $>0.05$ \\
\hline Adiponectin $[\mu \mathrm{g} / \mathrm{l}]$ & $93.59 \pm 230.96$ & $409.18 \pm 409.09$ & $<0.05$ \\
\hline Leptin [ng/ml] & $5.70 \pm 6.38$ & $7.19 \pm 6.95$ & $<0.05$ \\
\hline Ghrelin [ng/ml] & $80.99 \pm 32.26$ & $80.89 \pm 33.99$ & $>0.05$ \\
\hline
\end{tabular}


taneous Staphylococcus aureus infections [23], myalgias, and pseudotumor cerebri [24]. Frequently reported blood chemistry abnormalities in isotretinoin users include elevated levels of triglycerides and cholesterol [25], elevated LDL concentrations and decreased HDL concentrations [26]. In our current study, isotretinoin treatment often caused significant elevations in cholesterol, LDL-C, and triglycerides, which are comparable with results seen in the literature. However, we found no differences in $\mathrm{HDL}-\mathrm{C}$ levels after isotretinoin treatment.

There are very few clinical studies that investigated the effect of retinoic acids on BMI [11-15]. The results of previous clinical studies conflict with those of experimental studies $[10,27]$. In animal studies, retinoic acid induced decreases in body weight and fat loss despite unchanged or increased energy intake [27]. In contrast, clinical studies reported that BMI was unchanged [13] or increased [15] following retinoic acid. In the current study, we found no significant difference in pre- and posttreatment BMI values, which is comparable with the results of previous clinical studies.

Adiponectin is an adipocyte-derived hormone that plays a role in insulin function and energy homeostasis [28]. Early studies indicated that adiponectin has an antiinflammatory effect on endothelial cells by inhibiting the following: nuclear factor $\kappa \mathrm{B}$ activation [29], TNF-induced adhesion-molecule expression, vascular cell adhesion molecule-1, endothelial-leukocyte adhesion molecule-1 (E-selectin), and intracellular adhesion molecule-1 [30]. Adiponectin induces the secretion of some anti-inflammatory cytokines (e.g. interleukin (IL)-10 and IL-1 receptor antagonist) by human monocytes, macrophages and dendritic cells. Adiponectin can also suppress the production of interferon- $\gamma$ [31], while pro-inflammatory mediators, such as TNF- $\alpha$ and IL-6, inhibit adiponectin gene expression [30, 32]. To our knowledge, there are only 3 published studies relating isotretinoin treatment and adiponectin blood level [11-13]. All of these reports indicate that isotretinoin treatment leads to elevated levels of adiponectin. In the present study, patients had significantly elevated adiponectin levels after isotretinoin treatment, which is comparable with results of the literature. Increased adiponectin levels following isotretinoin treatment may contribute to the anti-inflammatory effects of isotretinoin.

Leptin is a 167 amino acid protein with a molecular weight of $16 \mathrm{kDa}$; it is mainly produced by the adipocytes that stem from the obese gene. Leptin levels are directly proportional to fat mass [33]. It is involved in the regulation of appetite and energy expenditure via hypothalamic-mediated effects [34]. In addition, it plays a role in carbohydrate and lipid metabolism [35]. Published data indicate that leptin levels are increased following acute infection and in chronic inflammation, which suggests that leptin may actively participate in the immune network and host defense [36]. In innate and adaptive immune systems, leptin can induce chemotaxis of neutrophils, increase the number of cluster of differentiation CD4+/CD8+ T lymphocytes, facilitate the development of natural killer cells, and promote T helper 1 (Th1) cell differentiation [37]. However, it has been reported that the paracrine/autocrine actions of leptin can be both pro- or anti-inflammatory in the adipose tissue. In addition, it has been found that leptin has a stimulatory effect on the expression of adiponectin, which is an anti-inflammatory cytokine [38]. Further, it has been shown that leptin may suppress the regulation of TNF- $\alpha$ expression in the adipose tissue [38]. Recently, Agak et al. reported that Th17 cells may play a role in acne pathogenesis [39]. Moraes-Vieira et al. investigated whether leptin mediates its activity on T cells by influencing dendritic cells to promote Th17 and Treg-cell immune responses in mice. They reported that local leptin increases dendritic cells and Th1 cells in vivo, but inhibits Th17 cells and Tregs cells [40]. To our knowledge, there is only one published study investigating the effect of isotretinoin treatment on insulin resistance and adipokines in patients with acne vulgaris [13]. Karadag et al. reported that basal leptin levels were significantly lower in the group with acne when compared to the control group, while basal adiponectin levels were significantly higher in the acne group. In our current study, we found that leptin was increased after isotretinoin treatment, which is not compatible with the results of Karadag et al. Our results indicate that the effects of isotretinoin may be due to the increase in leptin, which may act through the suppression of TNF- $\alpha$ expression, inhibition of Th17 cells and Tregs cells. Finally, all of these changes may generate anti-inflammatory responses. Further studies with greater numbers of patients are needed in order to determine whether changes in leptin levels are related with isotretinoin treatment, and further, whether the efficacy of isotretinoin treatment correlates with leptin levels.

Ghrelin is a recently-discovered orexigenic hormone that is primarily secreted by the stomach and duodenum; it has been implicated in both mealtime hunger and the long-term regulation of body weight [41]. Ghrelin is currently recognized as the main endogenous ligand for growth hormone secretagogue receptors as well as other regulatory factors in growth hormone secretion and energy balance [42]. The levels of circulating ghrelin increase under conditions of starvation and in anorexia nervosa, but decrease under conditions of feeding and in obesity [43]. Ghrelin and leptin may have opposite actions in the regulation of body weight $[44,45]$. Recently, it was reported that ghrelin exerts anti-inflammatory and immunoregulatory actions by inhibiting Ang II-induced expression of IL-8, TNF- $\alpha$ and monocyte chemoattractant protein-1 (MCP-1) [46]. Previously, ghrelin blood levels have not been evaluated in patients with acne vulgaris and in patients who were treated with isotretinoin. In the current study, we did not find any statistically significant 
difference in ghrelin levels as they relate to isotretinoin treatment. Therefore, our data suggest that isotretinoin has no effect on ghrelin levels.

\section{Conclusions}

This study revealed that isotretinoin treatment does not affect BMI. Additionally, adiponectin and leptin serum levels were significant increased with isotretinoin treatment. Prior to the current study, serum leptin and adiponectin levels in acne patients were investigated in only one study, which reported that leptin levels decreased, while adiponectin levels increased with isotretinoin treatment [13]. In our current study, adiponectin levels were similarly increased after isotretinoin treatment. However, we found that leptin levels were increased with treatment, which is in contrast with previously published data. Further, we found that ghrelin levels were not changed with isotretinoin treatment. Isotretinoin may exert its anti-inflammatory properties by increasing levels of leptin and adiponectin. New studies are required to discover the mechanism of action of those molecules in the pathogenesis of acne and in isotretinoin treatment.

\section{Conflict of interest}

The authors declare no conflict of interest.

\section{References}

1. Burton JL, Cunliffe WJ, Stafford I, Shuster S. The prevalence of acne vulgaris in adolescence. Br J Dermatol 1971; 85: $119-26$.

2. Collier CN, Harper JC, Cafardi JA, et al. The prevalence of acne in adults 20 years and older. J Am Acad Dermatol 2008; 58: 56-9.

3. Rigopoulos D, Larios G, Katsambas AD. The role of isotretinoin in acne therapy: why not as first-line therapy? Facts and controversies. Clin Dermatol 2010; 28: 24-30.

4. Emiroğlu N, Cengiz FP, Kemeriz F. Insulin resistance in severe acne vulgaris. Postep Derm Alergol 2015; 32: 281-5.

5. Williams HC, Dellavalle RP, Garner S. Acne vulgaris. Lancet 2012; 379: 361-72

6. Harrison WJ, Bull JJ, Seltmann H, et al. Expression of lipogenic factors galectin-12, resistin, SREBP-1, and SCD in human sebaceous glands and cultured sebocytes. I Invest Dermatol 2007; 127: 1309-17.

7. Nelson AM, Gilliland KL, Cong Z, Thiboutot DM. 13-cis retinoic acid induces apoptosis and cell cycle arrest in human SEB-1 sebocytes. J Invest Dermatol 2006; 126: 2178-89.

8. Bonet ML, Ribot J, Felipe F, Palou A. Vitamin A and the regulation of fat reserves. Cell Mol Life Sci 2003; 60: 1311-21.

9. Villarroya F, Giralt M, Iglesias R. Retinoids and adipose tissues: metabolism, cell differentiation and gene expression. Int J Obes Relat Metab Disord 1999; 23: 1-6.

10. Krskova-Tybitanclova K, Macejova D, Brtko J, et al. Short term 13-cis-retinoic acid treatment at therapeutic doses elevates expression of leptin, GLUT4, PPARgamma and aP2 in rat adipose tissue. J Physiol Pharmacol 2008; 59: 731-43.
11. Koistinen HA, Remitz A, Koivisto VA, Ebeling P. Paradoxical rise in serum adiponectin concentration in the face of acid-induced insulin resistance 13-cis-retinoic. Diabetologia 2006; 49: 383-6.

12. Heliövaara MK, Remitz A, Reitamo S, et al. 13-cis-retinoic acid therapy induces insulin resistance, regulates inflammatory parameters, and paradoxically increases serum adiponectin concentration. Metabolism 2007; 56: 786-91.

13. Karadag AS, Ertugrul DT, Takci Z, et al. The effect of isotretinoin on retinol-binding protein 4 , leptin, adiponectin and insulin resistance in acne vulgaris patients. Dermatology 2015; 230: 70-4.

14. Ertugrul DT, Karadag AS, Tutal E, Akin KO. Isotretinoin does not induce insulin resistance in patients with acne. Clin Exp Dermatol 2011; 36: 124-8.

15. Cetinözman F, Aksoy DY, Elçin G, Yıldız BO. Insulin sensitivity, androgens and isotretinoin therapy in women with severe acne. J Dermatolog Treat 2014; 25: 119-22.

16. Adityan B, Kumari R, Thappa DM. Scoring systems in acne vulgaris. Indian J Dermatol Venereol Leprol 2009; 75: 323-6.

17. Merrill BJ, Gat U, DasGupta R, Fuchs E. Tcf3 and Lef1 regulate lineage differentiation of multipotent stem cells in skin. Genes Dev 2001; 15: 1688-705.

18. Smith KR, Thiboutot DM. Thematic review series: skin lipids. Sebaceous gland lipids: friend or foe? I Lipid Res 2008; 49: 271-81.

19. Karadag AS, Ertugrul DT, Tutal E, Akin KO. Short-term isotretinoin treatment decreases insulin-like growth factor-1 and insulin-like growth factor binding protein-3 levels: does isotretinoin affect growth hormone physiology? Br J Dermatol 2010; 162: 798-802.

20. Stewart ME, Benoit AM, Stranieri AM, et al. Effect of oral 13-cis-retinoic acid at three dose levels on sustainable rates of sebum secretion and on acne. J Am Acad Dermatol 1983; 8: $532-8$.

21. King K, Jones DH, Daltrey DC, Cunliffe WJ. A double-blind study of the effects of 13-cis-retinoic acid on acne, sebum excretion rate and microbial population. Br J Dermatol 1982; 107: 583-90.

22. DiGiovanna JJ. Systemic retinoid therapy. Dermatol Clin 2001; 19: 161-7.

23. Leyden JJ, James WD. Staphylococcus aureus infection as a complication of isotretinoin therapy. Arch Dermatol 1987; 123: 606-8.

24. Kim RH, Armstrong AW. Current state of acne treatment: highlighting lasers, photodynamic therapy, and chemical peels. Dermatol Online J 2011; 17: 2.

25. Cisneros FJ, Gough BJ, Patton RE, Ferguson SA. Serum levels of albumin, triglycerides, total protein and glucose in rats are altered after oral treatment with low doses of 13-cis-retinoic acid or all-trans-retinoic acid. J Appl Toxicol 2005; 25: 470-8.

26. Laker MF, Green C, Bhuiyan AK, Shuster S. Isotretinoin and serum lipids: studies on fatty acid, apolipoprotein and intermediary metabolism. Br J Dermatol 1987; 117: 203-6.

27. Bonet ML, Ribot J, Palou A. Lipid metabolism in mammalian tissues and its control by retinoic acid. Biochim Biophys Acta 2012; 1821: 177-89.

28. Saltiel AR. You are what you secrete. Nat Med 2001; 7: 887-8.

29. Ouchi N, Kihara S, Arita Y, et al. Novel modulator for endothelial adhesion molecules: adipocyte-derived plasma protein adiponectin. Circulation 1999; 100: 2473-6.

30. Ouchi N, Walsh K. Adiponectin as an anti-inflammatory factor. Clin Chim Acta 2007; 380: 24-30. 
31. Wolf AM, Wolf D, Rumpold $H$, et al. Adiponectin induces the anti-inflammatory cytokines IL-10 and IL-1RA in human leukocytes. Biochem Biophys Res Commun 2004; 323: 630-5.

32. Carbone F, La Rocca C, Matarese G. Immunological functions of leptin and adiponectin. Biochimie 2012; 94: 2082-8.

33. Zhang Y, Proenca R, Maffei M, et al. Positional cloning of the mouse obese gene and its human homologue. Nature 1994; 372: 425-32.

34. Morton GJ, Schwartz MW. Leptin and the central nervous system control of glucose metabolism. Physiol Rev 2011; 91: 389-411.

35. Sweeney G. Leptin signalling. Cell Signal 2002; 14: 655-63.

36. Sarraf P, Frederich RC, Turner EM, et al. Multiple cytokines and acute inflammation raise mouse leptin levels: potential role in inflammatory anorexia. J Exp Med 1997; 185: 171-5.

37. Nawrocki AR, Scherer PE. Keynote review: the adipocyte as a drug discovery target. Drug Discov Today 2005; 10: 1219-30.

38. Li J, Li F, Zhao A. Inflammation and leptin. Drug Discovery Today: Disease Mechanisms 2006; 3: 387-93.

39. Agak GW, Qin M, Nobe J, et al. Propionibacterium acnes induces an IL-17 response in acne vulgaris that is regulated by vitamin A and vitamin D. J Invest Dermatol 2014; 134: 366-73.

40. Moraes-Vieira PM, Larocca RA, Bassi EJ, et al. Leptin deficiency impairs maturation of dendritic cells and enhances induction of regulatory T and Th17 cells. Eur I Immunol 2014; 44: 794-806.

41. De Ambrogi M, Volpe S, Tamanini C. Ghrelin: central and peripheral effects of a novel peptydil hormone. Med Sci Monit 2003; 9: 217-24.

42. Nogueiras R, Perez-Tilve D, Wortley KE, Tschöp M. Growth hormone secretagogue (ghrelin-) receptors: a complex drug target for the regulation of body weight. CNS Neurol Disord Drug Targets 2006; 5: 335-43.

43. Muccioli G, Tschöp M, Papotti M, et al. Neuroendocrine and peripheral activities of ghrelin: implications in metabolism and obesity. Eur J Pharmacol 2002; 440: 235-54.

44. Shintani M, Ogawa Y, Ebihara K, et al. Ghrelin, an endogenous growth hormone secretagogue, is a novel orexigenic peptide that antagonizes leptin action through the activation of hypothalamic neuropeptide $\mathrm{Y} / \mathrm{Y} 1$ receptor pathway. Diabetes 2001; 50: 227-32.

45. Kim BJ, Sohn JW, Park CS, et al. Body weight and plasma levels of ghrelin and leptin during treatment with olanzapine. J Korean Med Sci 2008; 23: 685-90.

46. Deng B, Fang F, Yang T, et al. Ghrelin inhibits Angll-induced expression of TNF-alpha, IL-8, MCP-1 in human umbilical vein endothelial cells. Int J Clin Exp Med 2015; 8: 579-88. 